\title{
Kajian Pustaka: Potensi Hypnosis untuk Mengurangi Nyeri pada Pasien yang Mendapatkan Perawatan Gigi dan Mulut
}

(Literature Review: The Potential of Hypnosis to Reduce Pain in Patients receiving Dental and Oral Care)

Eko Mulyadi

Fakultas IImu Kesehatan Universitas Wiraraja

\section{Abstrak}

Tujuan literature review ini untuk mengetahui apakah hypnosis dapat digunakan untuk mengurangi nyeri pasien yang mendapatkan perawatan gigi dan mulut. Hypnosis telah digunakan untuk menangani nyeri akut maupun kronis, kecemasan, dan manfaat positif lainnya sebelum, selama dan sesudah operasi. Namun di lapangan penggunaan hypnosis masih sedikit digunakan bahkan masih banyak yang meragukan efektifitasnya. Kami melakukan review artikel dalam bahasa inggris menggunakan kata kunci: hypnosis, pain, anesthesia, dental, procedure dengan rentang waktu dari 1846 hingga 2019, dengan 20 artikel terpilih di google cendekia, pubmed, science direct, dan portal perpustakaan nasional republik Indonesia (PNRI). Mesmerism hypnosis dan Ericsonian hypnosis sudah digunakan untuk anastesi sejak dahulu sebelum ditemukan anatesi kimia, penggunaan anastesi kimia membuat hypnosis tidak lagi digunakan sebagai anastesi utama dalam operasi, namun pada kasus tertentu seperti pasien dengan multiple chemical sensitivity atau pasien dengan kontra indikasi general anastesi, hypnosis tetap digunakan sebagai anastesi utama dalam operasi, saat ini hypnosis banyak digunakan pada peri operatif. Penggunaan hypnosis bersama anastesi kimia dapat meningkatkan manfaatnya dan tidak ada laporan efek samping. Kesimpulan: hypnosis dapat digunakan sebagai anastesi utama, terutama pada kasus tertentu, perlu penelitian dengan desain yang baik seperti randomized control trial tentang penggunaan hypnosis bersama anastesi kimia, baik peri operasi maupun intra operasi untuk mendapatkan informasi ilmiah lebih jelas dan konsisten tentang hypnosis dan anastesi kimia.

Kata kunci : hypnosis, gigi, nyeri, mulut

\section{Abstract}

The purpose of this literature review is to find out whether hypnosis can be used to reduce pain in patients receiving dental and oral care. Hypnosis has been used to treat acute and chronic pain, anxiety, and other positive benefits before, during and after surgery. However, in the field, the use of hypnosis is still little used and even many who doubt its effectiveness. We reviewed articles in English using keywords: hypnosis, pain, anesthesia, dental, procedure with a time span from 1846 to 2019, with 20 selected articles on google scholars, pubmed, science direct, and the national library portal of the republic of Indonesia (PNRI). , Mesmerism hypnosis and Ericsonian hypnosis have been used for anesthesia for a long time before chemical anesthesia was discovered, the use of chemical anesthesia makes hypnosis no longer used as the main anesthetic in surgery, but in certain cases such as patients with multiple chemical sensitivity or patients with contraindications for general anesthesia, hypnosis still used as the primary anesthetic in surgery, currently hypnosis is widely used in perioperative surgery. The use of hypnosis with chemical anesthetics can increase the benefits and there are no reported side effects. Conclusion: hypnosis can be used as primary anesthesia, especially in certain cases, it needs well-designed research such as randomized control trials on the use of hypnosis with chemical anesthetics, both perioperatively and intraoperatively to obtain clearer and consistent scientific information about hypnosis and chemical anesthetics.

Keywords: hypnosis, mouth, pain, teeth,

Korespondensi (Correspondence) : Eko Mulyadi. Fakultas IImu Kesehatan, Universitas Wiraraja. Jl. Raya SumenepPamekasan KM. 05 Patean, Sumenep, 69451, Email: eko.wiraraja@gmail.com

Hypnosis sudah digunakan di berbagai disiplin ilmu termasuk di kedokteran dan kesehatan. Hypnosis telah digunakan untuk menangani nyeri akut maupun kronis, kecemasan, dan manfaat positif lainnya sebelum, selama dan sesudah operasi.' Namun di lapangan penggunaan hypnosis masih sedikit digunakan bahkan masih banyak yang meragukan efektifitasnya, masih banyak yang percaya bahwa hypnosis merupakan ilmu yang berhubungan dengan kekuatan gaib, bantuan jin dan kuasa gelap, ditambah penggunaan hypnosis untuk kejahatan, seperti penipuan, pencurian, gendam, perampokan, membuat citra hypnosis menjadi buruk, masyarakat mendapat informasi yang salah tentang hypnosis. Padahal hypnosis mempunyai potensi yg besar untuk membantu pasien mengurangi nyeri, mengurangi kecemasan sehingga punya potensi besar untuk pasien yang mendapatkan perawatan gigi dan mulut.

Kajian pustaka penting untuk memberikan jawaban ilmiah dari pertanyaan besar yang sering ditanyakan oleh praktisi dan ilmuwan yaitu apakah hypnosis dapat digunakan untuk mengurangi nyeri pada pasien yang mendapatkan perawatan gigi dan mulut. Kami melakukan review artikel dalam bahasa inggris dalam bentuk full text dan abstract menggunakan kata kunci: hypnosis, anaesthesia, operation, dengan rentang waktu dari 1846-2019, di google cendekia, pubmed, science direct, dan portal Perpustakaan Nasional Republik Indonesia (PNRI), jurnal dengan terbitan lama untuk mengidentifikasi penggunaan hypnosis. Sebagai bahan diskusi kami mencari informasi dari buku, disertasi, bahan tak terpublikasi dan pengalaman pribadi sebagai praktisi hypnosis, kami hanya mengambil peer reviewed article 
dan publisher terpercaya, kami mengeluarkan artikel yang dari peneliti undergraduate atau yang meragukan hasil penelitiannya, akhirnya didapatkan 20 artikel yang sesuai kemudian kami sitensis dan jelaskan di dalam kajian pustaka ini.

\section{KAJIAN PUSTAKA}

Mesmerism hypnosis Untuk Mengurangi Nyeri Pada Pasien Yang Mendapatkan Perawatan Gigi Dan Mulut

Hypnosis telah digunakan sejak lama sebagai pengurang nyeri dan anastesi utama dalam berbagai operasi, pada era tersebut pendekatan mesmerism, merupakan tehnik hypnosis tertua yang pernah ada, tehnik ini diciptakan oleh franz anton Mesmer, Tehnik ini biasanya menggunakan bandul, koin atau objek berwarna terang untuk memfokuskan perhatian pasien. Pasien diminta untuk mengosongkan pikiran dan diperintahkan untuk menutup mata. ${ }^{2}$ Meskipun tidak dapat diverifikasi hypnosis diduga telah digunakan sejak 12 April 1829, ketika Jules Cloquet melakukan mastectomy di Paris. pada tahun 1836 diduga dilakukan dental surgery oleh Dr. harwood di Boston. Dua tahun kemudian hypnoanesthesia mulai digunakan di England yang mungkin oleh John Elliotson. ${ }^{3}$ Publikasi pertama tentang penggunaan hypnosis dilaporkan oleh james esdaile (1846) menyebutkan telah melakukan 73 operasi tanpa nyeri menggunakan hypnosis 4 yang membuktikan kesuksesan luar biasa dari hypnosis, mesmerism seringkali digunakan sebagai anastesi utama dalam operasi besar. ${ }^{1}$

Hypnosis dilaporkan digunakan sebagai anastesi utama untuk mengangkat tumor kulit pada pasien dengan multiple chemical sensitivity pada saat operasi nadi dan tekanan darah tidak naik. Ketika pasien selesai di hypnosis pasien juga mengatakan tidak merasakan sakit, dan keluar dari rumah sakit dengan segera. 5 Hypnosis juga dilaporkan digunakan bersama obat anastesi dan penenang untuk lingua resection dan thoracothomy. dari uraian diatas tampak hypnosis memang digunakan sejak lama untuk anastesi utama pada operasi besar, bahkan hypnosis merupakan senjata utama dokter bedah untuk melakukan operasi dan menghilangkan nyeri, hypnosis juga bisa digunakan bersama obat lainya untuk meningkatkan efektifitasnya dan tidak ada laporan komplikasi dari penggabungan tersebut, penelitian tentang hypnosis juga sudah mulai berkembang sejak dulu, menggambarkan bahwa dunia ilmiah sudah menerima hypnosis sebagai intervensi ilmiah.

Hypnosis bukan hanya berguna untuk mengurangi nyeri, juga untuk mengurangi kecemasan, mempercepat fase recovery hingga meningkatkan kualitas hidup. ${ }^{6}$ penggunaan mesmerism hypnosis untuk mengurangi nyeri pada pasien yang mendapatkan perawatan gigi dan mulut dapat menggunakan tehnik bahasa non verbal, seperti sentuhan, penggunaan bandul atau benda lain untuk memfokuskan pasien saat perawatan gigi, tehnik ini juga bisa digunakan untuk anak anak yang belum bisa berkomunikasi secara verbal.

Ericsonian Hypnosis Untuk Mengurangi Nyeri Pada Pasien Yang Mendapatkan Perawatan Gigi Dan Mulut

Berbeda dengan mesmerism, hypnosis ericsonian menginduksi hanya dengan kata kata, tehnik tersebut ditemukan dan dikembangkan oleh Milton $\mathrm{H}$ Erickson, Erickson percaya bahwa ada kesadaran berubah pada kondisi hypnosis dan penggunaan suggesti tidak langsung lebih baik daripada sugesti langsung. Erickson juga menemukan bahwa hipnosability (kemampuan untuk focus dan mengikuti sugesti) mempengaruhi proses hypnosis, pendekatan erisonian memberikan dampak yang sangat signifikan pada praktisi klinis dalam 2 dekade tekahir.?

Dalam sebuah laporan kasus disampaikan bahwa hypnosis digunakan sebagai anastesi tunggal untuk operasi gigi pada pasien dengan alergi obat. Operasi tersebut berjalan lancar dan terdapat efek lain yang menguntungkan yaitu pasien merasa lebih nyaman, mampu menyesesaikan mesalah pasien dan koping pasien membaik dan keyakinan untuk sembuh meningkat. Penggunaan hypnosis ericsonian juga digunakan dalam berbagai operasi lain, dilaporkan hypnosis digunakan dalam operasi cervikotomi, dan mendapatkan kondisi yang lebih baik, hanya 2 kasus dari 197 kasus membutuhkan konversi dari hypnosis menggunakan general anastesi. Semua pasien yang menggunakan hypnosis melaporkan pengalaman yang menyenangkan. Hospital stay juga berkurang signifikan disertai pengurangan biaya perawatan, Penyembuhan pasca operasi meningkat secara signifikan setelah hypnosis dan pengembalian penuh ke aktivitas sosial atau profesional secara signifikan lebih cepat, komplikasi seperti nausea dan vomiting juga menurun secara signifikan. ${ }^{8}$

Sebuah studi kasus menyebutkan bahwa hypnosis digunakan sebagai anastesi utama dalam operasi simple mastektomi, operasi tersebut berjalan lancar tanpa komplikasi, hypnosis juga digunankan oleh dokter bedah yang melakukan operasi sekaligus melakukan hypnosis, dia adalah seorang surgeon sekaligus hypnotherapist terlatih, disebutkan bahwa penjelasan kepada tim operasi tentang tahapan hypnosis dan operasi menjadi hal penting dalam keberhasilan penggunaan hypnosis sebagai anastesi utama dalam operasi.9 Sebuah studi kasus melaporkan keberhasilan hypnosis sebagai anastesi pada operasi katarak, pada wanita 73 tahun yang kontra indikasi general anastesi. induksi menggunakan tehnik heavy eyelid, dan pasien masuk dalam kondisi trance hanya dalam waktu 30 detik, dilanjutkan dengan contonius relaxation suggestion, hingga 
operasi selesai, pasien melaporkan tidak sadar tentang operasi yang telah dilakukan. ${ }^{10}$

Dari uraian diatas tampak bahwa hypnosis erisconian dapat digunakan untuk anastesi utama pada operasi. Pendekatan eriksconian juga lebih diterima dalam dunia ilmiah karena lebih masuk akal, ericksonian tidak bertitik pada kondisi trance ( kesadaran berubah dalam kondisi pasien terhipnosis) yang sangat dalam, bahkan dapat digunakan pada saat pasien masih sadar penuh. Dengan kelebihan ini ericsonian banyak diadopsi oleh klinisi lain karena lebih mudah dilakukan dan lebih luas penggunaannya. Seperti untuk mengurangi nyeri, kecemasan, bahkan untuk merubah persepsi dan perilaku.

\section{PEMBAHASAN}

\section{Hypnosis versus chemical anesthesia}

Dokter bedah pernah mengandalkan hypnosis dalam prosedur operasi sebelum anastesi kimia ditemukan. Namun penemuan ether dan nitrous oxide tampaknya telah membuat hypnosis tidak lagi digunakan dalam prosedur bedah. Penggunaan eter untuk operasi dimulai pada tahun 1846, penerapannya lebih mudah, dan sederhana, efeknya lebih mudah diprediksi dan dikontrol yang membuat metode anastesi lebih simple, membuat hypnosis menjadi memiliki reputasi rendah dan kurang dipercaya, ada beberapa orang melihat hypnosis merupakan hal yang eksotis, yang hanya dapat digunakan oleh orang terlatih, bahkan celakanya hypnosis dianggap menggunakan kekuatan gaib dan ilmu hitam.

Penggunaan hypnosis biasanya membutuhkan waktu setengah jam hingga satu jam untuk memulai induksi hypnosis pada kebanyakan pasien, ditambah lagi lingkungan, focus, kemauan pasien akan mempengaruhi keberhasilan hypnosis, hal inilah yang menjadi penyebab hypnosis menjadi tidak popular dan perlahan ditinggalkan oleh anastesiest." Meskipun demikian, hypnosis memililiki kelebihan biaya yang murah, memiliki efek samping yang menguntungkan seperti mengurangi kecemasan, meningkatkan relaksasi hingga pasien dapat kembali beraktivitas sosial atau profesional secara signifikan lebih cepat. ${ }^{8}$ hypnosis juga bisa digunakan untuk pasien dengan kontra indikasi general anastesi, seperti alergi obat anastesi. 5

Pada kondisi darurat dimana obat anastesi tidak didapatkan hypnosis tetap bisa di andalkan. Anastesi kimia juga mempunyai beberapa kekurangan, resiko komplikasi penggunaan anastesi kimia, mulai nausea, vomiting ileus, gangguan fungsi paru, meningkatkan cardiac demand dan resiko thromboembolism. ${ }^{12}$ Penelitian lain yang membandingkan general anastesi dan spinal anastesia menyebutkan bahwa spinal anastesia membutuhkan lebih sedikit transufi darah, dan lebih sedikit kejadian thrombosis deep vein, urinary track infection lebih rendah dan komplikasi lain lebih rendah. ${ }^{13}$ Hal ini menyadarkan anestesiest lebih berhati hati menggunakan general anastesi dan mulai menggunakan short acting anaesthesi, spinal anesthesia hingga local anaesthesia, reaksi anafilaksis selama anstesi adalah komplikasi serius untuk pasien dan anastesiest, diperkirakan 1 dari 10.000 pasien mengalami insiden reaksi anafilaksis, dan tidak ada laporan anafilaksis dari anastesi local. ${ }^{14}$

Dari uraian diatas tampak bahwa hypnosis dan anastesi kimia memiliki kekurangan dan kelebihanya masing masing, penelitian terdahulu juga menyebutkan bahwa hypnosis dapat digabungkan dengan anastesi kimia, jika anastesi kimia pernah membuat hypnosis ditinggalkan, maka menggabungkan hypnosis dengan anastesi kimia dapat mengembalikan hypnosis dalam popularitasnya. Praktisi juga dapat memiliki pilihan yang lebih banyak dalam anaestesi,

\section{Penggunaan Hypnosis dalam perioperative}

Setelah hypnosis mulai ditinggalkan penggunaannya di intraoperasi, Saat ini hypnosis bangkit kembali di perioperasi, psikologi dan kejiwaan, penggunaan ericsonian hypnosis yang dapat diterapkan bahkan pada saat pasien masih sadar membuat penerapan hypnosis semakin meluas, salah satunya conversational hypnosis, hypnosis ini bahkan dapat digunakan saat anamnese dan pasien dalam kondisi sadar penuh, hasil penelitian tentang conversational hypnosis dapat mengurangi kecemasan sebelum dan sesudah operasi. ${ }^{15}$ Hypnosis juga dilaporkan dapat mengurangi perdarahan, memicu perilaku konstruktif dan meningkatkan harapan dan kemauan untuk sembuh.16 Bahkan hypnosis dapat digunakan untuk premedikasi pada anak yang akan di operasi, dilaporkan hypnosis sama efektifnya dengan obat premedikasi midazolam, untuk mengurangi kecemasan dan gangguan perilaku selama dan sesudah operasi. ${ }^{17}$

Hypnosis merupakan tindakan yang efektif dan feasible digunakan untuk intervensi invasif yang sering digunakan dalam perioperative seperti transesophageal echocardiography, dilaporkan sebagai alternatif yang baik pengganti general anastesi. ${ }^{18}$ Poin penting peran hypnosis dalam perioperative adalah manajemen nyeri. ${ }^{19}$ Nyeri merupakan keluhan utama pasien, maka hypnosis mempunyai potensi besar dalam manajemen nyeri. Hypnosis juga mempunyai potensi untuk digunakan dalam persalinan. hypnosis dapat mengurangi penggunaan obat analegesia secara keseluruhan dalam proses persalinan, namun jumlah penelitian penggunaan hypnosis dalam persalinan masih relatif sedikit, dibutuhkan penelitian dengan riset dengan metode randomized control trial yang baik. ${ }^{20}$ Dari uraian diatas tampak bahwa hypnosis dapat digunakan dalam perioperative, dengan peran utama mengurangi nyeri, hypnosis juga dapat mengurangi kecemasan sebelum operasi, 
membuat perilaku yg kontruktif hingga meningkatkan harapan dan kemauan untuk sembuh, Semua manfaat ini menguntungkan untuk pasien dan praktisi, meskipun masih dibutuhkan penelitian lebih lanjut khususnya dalam persalinan, hypnosis dapat berperan besar dalam perioperative.

Hypnosis dapat digunakan untuk mengurangi nyeri untuk perawatan pasien gigi dan mulut, bahkan untuk anestesi utama, terutama dalam kasus spesifik seperti pasien multiple chemical sensitive, atau pada kondisi tidak tersedia obat anastesia, melihat perkembangan obat anastesi kimia saat ini, hypnosis juga dapat digunakan bersama anastesi kimia, hypnosis juga dapat digunakan dalam perioeprative untuk mengurangi kecemasan sebelum operasi dan mengurangi nyeri sesudah operasi,

\section{DAFTAR PUSTAKA}

1. Hammond D. Hypnosis as Sole Anesthesia for Major Surgeries: Historical \& Contemporary Perspectives. 2008; 51: 101.

2. Alpheus A. How to hypnotize: complete hypnotism, mesmerism, mind-reading and spiritualism [Internet]. Waiheke Island: Floating Press; 2009.

3. Hammond D (2013) A Review of the History of Hypnosis Through the Late 19th Century, American Journal of Clinical Hypnosis, 2013; 56(2): 174-91.

4. Hassan SZ, Waqas M, Yaqub D, Asad D. Hydrotherapy: an efficient and costeffective treatment for depression. International Journal Of Community Medicine And Public Health. 2016; 4(1): 274.

5. Facco E, Pasquali S, Zanette G, Casiglia E. Hypnosis as sole anaesthesia for skin tumour removal in a patient with multiple chemical sensitivity. Anaesthesia. 2013 ; 68(9): 961-5.

6. Fathi M., Hassani M., Jafari M., Joudi M., Habibzadeh R., \& Joudi M. Hypnosis as an Alternative to General Anesthesia for Orthopedic Hand Surgery: A Case Report. Annals of Anesthesiology and Critical Care, 2017; 2(1), 1-3.

7. Thuillier Lecouf A, Videloup L, Letrecher $S$, et al. [Ericksonian hypnosis and mindfulness meditation: Towards a behavioral medicine in nephrology]. Nephrologie \& Therapeutique. 2020; $16(2)$ : 93-6.

8. Badidi G, Baulieu M, Vercherin P, V. De Pasquale VD, Gavid M, Prades JM, Thyroid surgery under hypnosis: A 50-case series, European Annals of Otorhinolaryngology, Head and Neck Diseases. 2021; 138(1):1317.
9. Fiddaman J. Simple Mastectomy under Hypnosis: A Case Study Approach: Journal of Perioperative Practice [Internet]. 2016 Oct 1 [cited 2019 Jul 29]; Available from: https://journals.sagepub.com/doi/pdf/10 $.1177 / 175045891602601001$

10. Kiss G, Butler J. Hypnosis for Cataract Surgery in an American Society of Anesthesiologists Physical Status IV Patient. Anaesthesia and Intensive Care. 2011; 39(6):1139-41.

11. Yeates, L. B. James Braid (V): Chemical and hypnotic anaesthesia, psychophysiology, and Braid's final theories. Australian Journal of Clinical Hypnotherapy \& Hypnosis. 2018; 40(2), 112-167.

https://search.informit.org/doi/10.3316/inf ormit.326505573983891

12. Cozzolino M, Celia G, Rossi KL \& Rossi EL. Hypnosis as Sole Anesthesia for Dental Removal in a Patient with Multiple Chemical Sensitivity, International Journal of Clinical and Experimental Hypnosis. 2020; 68(3): 371-83.

13. Fields AC, Dieterich JD, Buterbaugh K, Moucha CS. Short-term complications in hip fracture surgery using spinal versus general anaesthesia. Injury. 2015 ;46(4): 719-23.

4. Anaesthesia, surgery, and life-threatening allergic reactions: epidemiology and clinical features of perioperative anaphylaxis in the 6th National Audit Project (NAP6) - ScienceDirect [Internet]. [cited 2019 Aug 2]. Available from: https://www.sciencedirect.com/science/ article/pii/S0007091218303180

15. Sourzac J, Berger V, Conri V. The impact of conversational hypnosis on the preand postoperative anxiety of patients in gynecological surgery versus ordinary practice: A comparative study. Recherche en soins infirmiers. 2018; 135(4):83-90.

16. Toma AG, Salahoru $P$, Hinganu MV, Hinganu D, Cozma LCD, Patrascu A, et al. Reducing the Duration and Improving Hospitalisation Time by Using New Surgical Tehniques and Psychotherapy. (1):4.

17. Calipel S, Lucas-Polomeni M-M, Wodey E, Ecoffey C. Premedication in children: hypnosis versus midazolam. Pediatric Anesthesia. 2005; 15(4):275-81.

18. Amedro P, Gavotto A, Gelibert D, Fraysse $\checkmark$, Villeon GDL, Vandenberghe $D$, et al. Feasibility of clinical hypnosis for transesophageal echocardiography in children and adolescents: European Journal of Cardiovascular Nursing [Internet]. 2018 Sep 19 [cited 2019 Jul 29]; 
Available from: https://journals.sagepub.com/doi/full/10. $1177 / 1474515118803513$

19. Rafiq M. Headache management through hypnosis: A case report. Intensive Care. 2018; 22: 4.

20. Madden K, Middleton P, Cyna AM, Matthewson M, Jones L. Hypnosis for pain management during labour and childbirth. Cochrane Database of Systematic Reviews [Internet]. 2016 [cited 2019 Aug 3];(5). Available from: https://www.cochranelibrary.com/cdsr/d oi/10.1002/14651858.CD009356.pub3/abs tract 